EPJ Web of Conferences 12, 01002 (2011)

DOI: $10.1051 /$ epjconf/20111201002

(C) Owned by the authors, published by EDP Sciences, 2011

\title{
Ageing management of french NPP civil work structures
}

\author{
E. Gallitre and D. Dauffer \\ EDF - SEPTEN Nuclear Engineering Department, 69100 Villeurbanne, France
}

\begin{abstract}
This paper presents EDF practice about concrete structure ageing management, from the mechanisms analysis to the formal procedure which allows the French company to increase $900 \mathrm{MWe}$ NPP lifetime until 40 years; it will also introduce its action plan for 60 years lifetime extension.

This practice is based on a methodology which identifies every ageing mechanism; both plants feedback and state of the art are screened and conclusions are drawn up into an "ageing analysis data sheet".

That leads at first to a collection of 57 data sheets which give the mechanism identification, the components that are concerned and an analysis grid which is designed to assess the safety risk. This analysis screens the reference documents describing the mechanism, the design lifetime hypotheses, the associated regulation or codification, the feedback experiences, the accessibility, the maintenance actions, the repair possibility and so one. This analysis has to lead to a conclusion about the risk taking into account monitoring and maintenance. If the data sheet conclusion is not clear enough, then a more detailed report is launched. The technical document which is needed, is a formal detailed report which summarizes every theoretical knowledge and monitoring data: its objective is to propose a solution for ageing management: this solution can include more inspections or specific research development, or additional maintenance. After a first stage on the 900 MWe units, only two generic ageing management detailed reports have been needed for the civil engineering part: one about reactor building containment, and one about other structures which focuses on concrete inflating reactions. The second stage consists on deriving this generic analysis (ageing mechanism and detailed reports) to every plant where a complete ageing report is required (one report for all equipments and structures of the plant, but specific for each reactor).

This ageing management is a continuous process because the 57 generic data sheets set is updated every year and the detailed generic reports every five years. After this 40 year lifetime extension, EDF is preparing a 60 years lifetime action plan which includes R\&D actions, specific industrial studies and also monitoring improvements.
\end{abstract}

\section{INTRODUCTION}

EDF PWR fleet consists of 58 Units in operation for an installed capacity of 63 GWe. At the end of 2010 , this fleet has an average age of approximately 26 years, the youngest unit 12 years and the oldest 33 years. The location of the plants can be seen on the figure 1 .

Environment effects and various type of phenomenon can cause ageing of NPP structures. If we do not implement at the appropriate time the necessary action to know the accurate status of the structures and the answer to control ageing, that may affect the performances and the duration of Unit operation.

The control of structures ageing is based at first on the quality of their design and their construction which makes possible to preserve from detrimental ageing phenomenon. But it is necessary to undertake an in depth analysis to screen every phenomenon with a rigorous methodology in order to guarantee safety during NPP lifetime.

Practically every nuclear country has developed a systematic program to deal with ageing of components on their plants [R1]. This article will present the all program developed by EDF to demonstrate the 900 MWe NPP ability to run for 40 years in a first time and then the main planned actions to control ageing for 60 years in the civil engineering field.

This is an Open Access article distributed under the terms of the Creative Commons Attribution-Noncommercial License 3.0, which permits unrestricted use, distribution, and reproduction in any noncommercial medium, provided the original work is properly cited. 


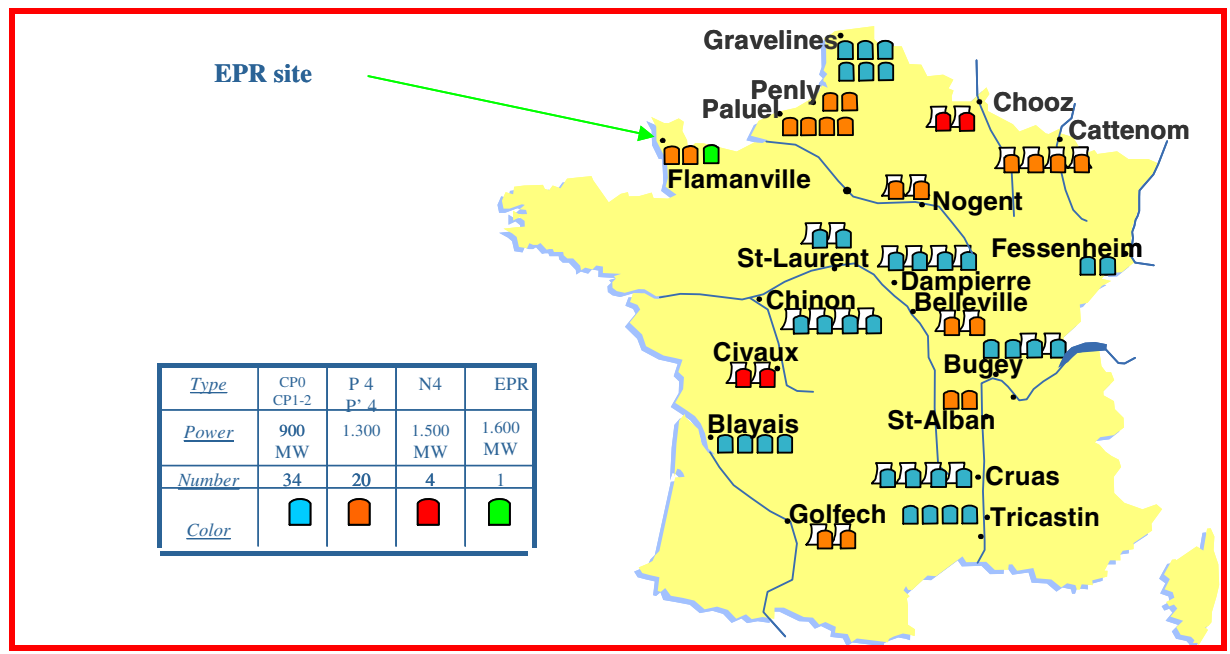

Figure 1. EDF NPP location.

Table 1. Civil work ageing identified mechanism.

\begin{tabular}{|l|l|}
\hline Structure, component or system & Sheet number \\
\hline Containment & 12 \\
\hline Equipment hatch \& Personnel air lock & 3 \\
\hline Penetration & 2 \\
\hline Transfer tube & 1 \\
\hline Civil Engineering structures and systems & 18 \\
\hline Pools & 3 \\
\hline Fire protection & 7 \\
\hline Embedded pipes & 3 \\
\hline Site specific structures & 8 \\
\hline
\end{tabular}

\section{40 YEARS LIFETIME JUSTIFICATION FOR 900 MWE FLEET CIVIL WORK STRUCTURES}

\subsection{Ageing mechanism identification}

The first step of this methodology (ref [1]) was to identify every mechanism which could affect civil work lifetime. But to perform this identification, the civil engineering had to be broken down in numerous components with their own ageing mechanism and sometimes possible positive or negative interaction such as for steel corrosion.

To simplify, components can be classified in the following families:

- Geotechnical elements

- Mineral component (aggregate and cement included)

- Metal component

- Organic component

- Manufactured complex component.

After a bibliographic studies phases, EDF engineering division and research department has identified 57 mechanisms which concerns the items which can be seen in the table 1: 
AMP 2010

Table 2. Mechanism "status" 0,1 or 2 depending on repair difficulty.

\begin{tabular}{|c|c|c|c|c|}
\hline $\begin{array}{c}\text { Degradation } \\
\text { Mechanism }\end{array}$ & Encountered & Encountered & Potential & Potential \\
\hline $\begin{array}{c}\text { Monitoring and } \\
\text { maintenance }\end{array}$ & Adapted & Difficult to adapt & Adapted & Difficult to adapt \\
\hline $\begin{array}{c}\text { Repair and } \\
\text { replacement very } \\
\text { difficult }\end{array}$ & $\mathbf{2}$ & $\mathbf{2}$ & $\mathbf{0}$ & $\mathbf{2}$ \\
\hline $\begin{array}{c}\text { Repair or } \\
\text { replacement very } \\
\text { difficult }\end{array}$ & $\mathbf{0}$ & $\mathbf{2}$ & $\mathbf{0}$ & $\mathbf{1}$ \\
\hline
\end{tabular}

\subsection{Ageing mechanism analysis}

The major objectives of this basic activity is to justify that the structures and associate systems concerned with ageing mechanism remain in the design and safety criteria, including all feedback from the field; another objective is to improve maintenance when needed.

So that the first step of this program is to identify each potential degradation mechanism, which can affect these structures or systems. In order to do that, the procedure consists in a specific grid with one line per potential degradation mechanism and the following information collected in the columns:

- Is the degradation mechanism potential or already encountered in French or other similar plant?

- Did we encounter difficulties that can have affected a safety function?

- Is the degradation mechanism analyzed in the design documents? And if yes, what is the expected lifetime?

- Is the present maintenance program adapted, easy to adapt or not adapted for this degradation mechanism?

- Is the repair easy or difficult for this degradation mechanism and this location?

- Is the replacement easy or difficult? Do we have any risk of obsolescence of the system?

A specific data sheet is attached to each line of the grid in order to collect all the references used to complete the grid.

At the end of the sheet, a conclusion, presented as a "status" of the mechanism is given, depending on the answer to the questions in the following table (for example: if the degradation mechanism has already been encountered in EDF or similar plants and if repair and replacement are very difficult, the mechanism status is " 2 ", even if monitoring \& maintenance actions are adapted):

After the allocation of the "status" on each sheet, the consequences are:

- For status 0: analyze is considered as sufficient

- For status 1: instruction is needed to qualified a status 0 or 2

- For status 2: an Aging Management Detailed Report is needed

As yet, only 2 mechanisms (or group of mechanism) have a status 2: these ones are:

- Containment: pre-stress losses and liner corrosion

- Every concrete structures: alkali-aggregate reaction.

These two reports have two stages: the first one is generic (only one report for the $900 \mathrm{MWe}$ series); the second one is local (one report per unit). The generic ones will be briefly summarized in the following chapters.

\subsection{Detail ageing mechanism justification}

\subsubsection{Containment example}

This report summarizes the containment design and particularly the pre-stress losses due to steel relaxation and the losses due to concrete shrinkage and creep. Liner design is also described, taking into 


\section{EPJ Web of Conferences}

account that even if it does not play any part in the resistance, it presents unfavorable aspects, concerning its action on the concrete. The liner mainly behaves under concrete imposed strain for permanent loads, and under thermal effect under accidental loads.

The liner thickness was mainly given by the no bucking condition under permanent loads: nevertheless, recent studies have shown that bucking is not a problem from a safety point of view.

Pre-stress losses:

On each EDF containment reactor building, there is a large monitoring system (strain censors) which measures strain in the three dimensions every two months on several areas (raft, dome, standard part...). These censors data have been recorded since the commissioning: so we have curves we can extrapolate until 40 years or more. The new studies done for the third decennial safety examination (taking into account severe accident for example) have taken these new extrapolated curves as new hypotheses to set shrinkage and creep assumptions. That is interesting to note that the steel liner confers to the concrete wall a virtual thickness that is the double as the real one for the drying effects.

As air tightness is given by the liner, such concrete long term strains have no consequences on safety.

$\underline{\text { Steel liner corrosion risk: }}$

Steel liner corrosion risk cannot be ignored because of the events that happened during the early $90^{\text {th }}$ in the lower part of the reactor building: a localized type corrosion happened near the basement and needed repair operations (but without impact on periodic air tightness test results): now the definitive operation which consisted in wax grouting has solved this problem.

An international survey has been undertaken after this event: this survey has confirmed our analyze that concluded to the link between corrosion and bad protection (void or gap just next to the liner without coating) in the bottom of the building.

As a conclusion, risk is controlled but periodic inspections are completed by ultrasonic thickness measurement in critical areas.

\subsubsection{Alkali-aggregate reaction example}

The alkali-aggregate reaction is an irreversible chemical reaction of concrete, but without any specification during the existing NPP design phase. As a matter of fact, concrete requirement (on aggregates) to avoid alkali-aggregate reaction date from the years 1994 and after.

This reaction is due to alkali and hydroxyls ions from Portland cement paste and certain reactive siliceous minerals that are often present in the aggregate. In literature, the phenomenon is referred to as alkali-silica reaction (ASR) (ref [2]). Pop-outs and exudation of a viscous alkali-silicate fluid are other manifestations of the phenomenon: the first paper about this subject was published by Stanton in 1940 from his investigation of cracked concrete structure in California, but has not been clearly explained at this moment. Later a dam in France (which belongs to EDF) has been affected and has been treated recently by a sawing procedure, allowing future concrete expansion.

So a risk scale has been established, on the base of different factors such as cement, aggregate and admixture chemical composition. Every site has been classified on this risk scale and only four among a total of 19 has been considered with potential risk. These sites are essentially located on the Loire River where aggregates contain a large part of silica. So these sites are inspected in order to detect ASR.

In case of serious problem, some solutions exist but are limited and not so adapted to nuclear facilities. By chance, this phenomenon is slow and can be detected by observations like pop-out or concrete expansion when the structure is instrumented as the reactor containment wall and raft: early detection is less obvious when there is no instrumentation except in reactor building. If ASR is detected, a methodology exists to follow its evolution: it consists in measuring crack length inside a fixed area, it is normalized and called "Trihedron" method. 


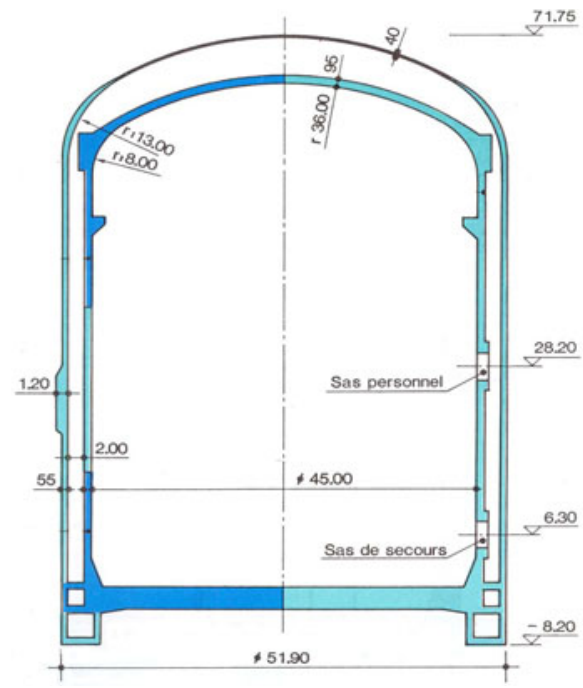

The double containment of reactor building consists in a first prestressed concrete wall with limited leak, a external concrete wall and safety ventilation system which guarantees a minimum vacuum in accidental condition.

A internal polymer liner has been put in place to improve pre-stressed wall tightness in specific areas.

Figure 2. Double wall containment principles.

A first analysis of potential consequences has been done, taking into account expansion and cracking of concrete leading to loss of strength and elastic modulus, the conclusions are the following ones:

- In medium term there is no dangerous consequence because of the large amount of reinforcement in the concrete

- In a longer term, inspections may be intensified if manifestations are detected, and more sophisticated analysis may be undertaken if necessary

- In long term, water tightness may be improved if necessary by metallic or organic coating.

Note on this subject, that EDF participates to a RILEM group, which focus on RSA and other expanding concrete reactions, which started in 2007.

\section{60 YEARS LIFETIME ACTION STRATEGY FOR ALL EDF FLEET CIVIL WORK STRUCTURES}

\subsection{General method: 40 years lifetime methodology extension}

The first step will be to extend the "40 years methodology" to 60 years. That means that we have to carry on ageing our lifetime diagnostic. Obviously some topics are still "open" today, so that we intend to improve our predictive models, but the idea is to keep a similar method.

\subsection{Supplementary actions in the containment field}

The main concern is the behavior in test or in accident condition of the double containment without metallic liner: a lot of solutions are studied or already put in place on site such as polymer liner on the inner face of the first wall.

Actually the action plan is based on the studies about the following items:

- The repair or replacement of strain measurement devices (outer face solution ready today)

- The improvement of predictive models 


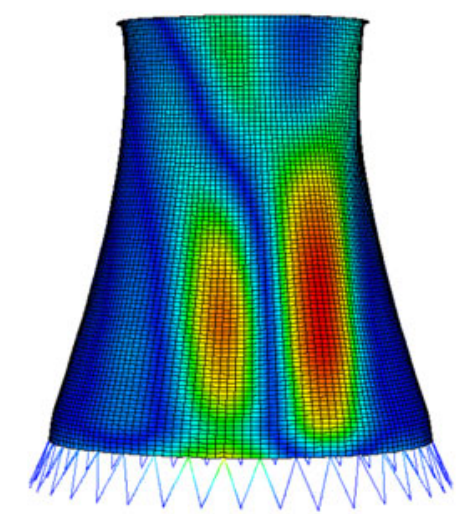

\begin{tabular}{|l|}
\hline -Thermal \\
•Drying \\
- Settlements \\
- Thin shell behavior and shape defects \\
$\quad$ evolution \\
- Reinforced concrete cracking \\
-Wind actions \\
-Steel corrosion and cracking corrosion \\
$\quad$ interaction \\
\end{tabular}

Figure 3. Involved phenomenon in cooling tower behavior.

- The improvement of global tightness (“direct” leak diminution with taps technology improvement)

- Improvement of between walls ventilation and treatment system

- Other in progress solutions.

EDF is confident in double wall containment reactors lifetime extension, but is performing industrial feasibility studies in order to choose the most suitable solutions.

For single wall containment reactors, EDF is caring on R\&D studies and partnership about specific steel corrosion in concrete environment conditions. And of course EDF is continuing to operate its full monitoring system in test and in normal conditions (mainly with permanent concrete strain recording system and steel liner inspections).

\subsection{Supplementary actions in the cooling towers field:}

As mentioned in the following diagram, the cooling towers behavior is a complex multi-factors phenomenon which deals with:

Due to such a complex problem, EDF has launched a working group gathering several experts in specific fields (actual cooling tower monitoring, structure engineers, wind actions research, reinforced concrete steel corrosion, ....). The main conclusion of this group (which is still in progress) is that the major risk for the EDF cooling towers fleet is the steel corrosion and its consequences on the structural ductility diminution.

Consequently the main supplementary action is an in situ inspection program to collect physical data which will be the input data of predictive models. Of course, the previous monitoring program is caring on with the settlements measurement, the shape defects photogrammetric recording, and the systematic optic inspections.

The only retrofitting actions which have already been performed in the EDF towers fleet was to control cracking evolution, mainly on the upper part of the tower (risk for corrosion and global rigidity loss): fibers solutions have been chosen because of their light weight and their anti-cracking efficiency.

\section{CONFORMITY TO INTERNATIONAL STANDARDS}

The main text which constitutes a international standard for Ageing Management of Nuclear Power Plants is the IAEA Guide NS-G-2.12 (ref. [3]) that gives every principles which have to be met to have a satisfactory plan. 
AMP 2010
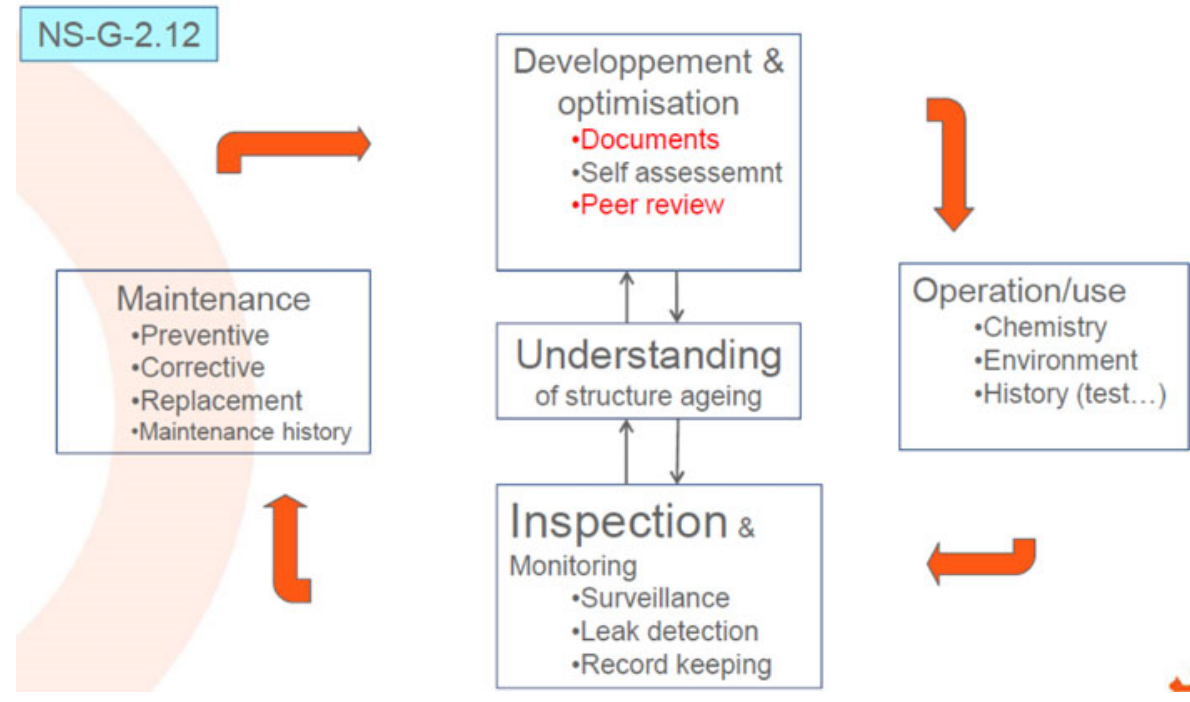

Figure 4. AMP basic organization.

This document emphasis on the organizational arrangements with the following basic condition for success: responsibility of each actor has to be clearly defined with the "virtuous" approach presented as a adaptation of the Deming's "Plan-Do-Check-Act" cycle, as you can seen in the fig. 4.

To summarize EDF inspection documents, we can say that there are generic notes which gave the target of the inspection, the scope, the frequencies and the type of verification which have to be performed, and then building specific documents which are written for each of them. There are obviously specific documents for containment with steel liner and others for the ones without steel liners.

Basically, the EDF organization as an "integrated" company with its own engineering division has been very helpful to put in place such a project.

The main idea is the "continuous" aspect of this process, with the following items which have to be pointed out:

- Systematic approach

- Early Implementation

- Pro-active approach

- Sense of ownership.

EDF approach is very near the US-NRC "GALL" (ref. [4]) approach, with the identification of a large number of mechanisms, with also the identification of the inspection document for each of them. The main difference is the format and the way to cross mechanism with location. But basically the two approaches seem to be very similar.

\section{CONCLUSION}

EDF has developed a specific procedure to review how the ageing phenomenon has to be treated from a safety point of view. This procedure has been applied to the 34 French 900 MWe units. The application to the civil engineering has been appreciated by the Safety Authority because of its systematic aspect, that leads to a documented discussion about every ageing mechanism. 
This procedure is based on ageing data sheets written on each mechanism: that can lead to more consistent reports if necessary for critical ones. These ones are analyzed through Aging Management Detailed Reports (for civil engineering: containment steel liner corrosion + pres-tress losses and AlkaliGranulate Reaction).

This general method will be adopted for 60 years lifetime extension with additional actions in different fields in order to validate such an extrapolation: obviously, these actions are still in progress.

The EDF approach is similar to the one proposed by NRC, but with differences about format. This approach meet easily the IAEA Safety Guide NS-G-2.12c requirements due to the fact that maintenance engineering is integrated in the global EDF of organization.

\section{References}

[1] Ageing Management of EDF NPP: from the design phase up to the end of life - $2^{\text {nd }}$ International Symposium on NPP Life Management, Shanghai Chine 2007 C Faidy.

[2] Concrete: Microstructure, Properties and Materials P Kumar Mehta McGraw-Hill Edition

[3] IAEA Safety Guide NS-G-2.12 Edition 2009 Ageing Management of Nuclear Power Plants

[4] US NRC NUREG 1801 rev 2 Generic Aging Lessons Learned (GALL) Report 